\title{
Attentional control of visual suffix effects
}

\author{
SUSAN KARP MANNING \\ Hunter College and the Graduate Center of the City University of New York, New York
}

\begin{abstract}
An experiment was performed to compare the effects of an attentional manipulation and four suffix conditions on the recall of auditorily presented numerical sequences. In the nonattention condition, in which a suffix was described as a recall cue, spoken suffixes produced large end-ofsequence performance decrements; lipread suffixes produced similar, although smaller, effects. Suffixes "drawn" through the air on a card background (drawn) and those printed on a card (graphic) led to no significant end-of-sequence effects. In the attention condition, a suffix-prefix (the subject recalled the suffix, which was either 0 or 9 , before commencing recall) was used to compel attention. The attentional manipulation led to changes in performance on sequences having lipread or drawn suffixes but not for those having graphic or spoken suffixes. The finding that attentional factors affect the size of lipread but not spoken end-of-sequence suffix effects suggests differences between auditory and visual suffix effects. Similarly, the differences in preterminal suffix effects resulting from the attentional manipulation suggest differences among various visual stimuli in sensitivity to generalized interference.
\end{abstract}

Recency is defined as superior performance on the most recently presented items in a sequence. A suffix is defined as an extra, not-to-be-recalled item added onto a sequence. When sequences are presented in the auditory mode and when serial recall is required, recency usually results. When an auditory suffix is presented, an end-of-sequence decrement occurs and recency is usually reduced or eliminated. When the mode of presentation is visual, however, recency is generally absent and a suffix usually produces either no effect or a much smaller, more generalized effect.

Crowder and Morton (1969) developed a theory that linked recency and end-of-sequence suffix effects. Specifically, they hypothesized that auditory recency was the result of lasting sensory traces generated by auditory stimuli. Subjects had access to these traces and through a rehearsal mechanism, before they began recall, gained an advantage for the final item or items in the sequence. The suffix reduced or eliminated access to this information, thus leading to the end-of-sequence effect. According to this view, visually presented stimuli acted differently because the sensory traces generated were hypothesized to last such a brief time that they were of no informational value to the subject. This modality difference was used by Crowder and Morton to explain both the lack of visual recency and the lack of end-of-sequence suffix effects for visual stimuli. Additionally, this view predicted that visual suffixes would have no effect on auditory sequences because such stimuli would not block auditory sensory traces.

\footnotetext{
The author wishes to thank Tracey Roberts for her work on this project. Some support for this project was provided by a Shuster Faculty Research Award from Hunter College. This paper was presented at the Meeting of the Psychonomic Society, San Diego, November 1983. Please address reprint requests to Susan Karp Manning, Department of Psychology, Hunter College, 695 Park Avenue, New York, NY 10021.
}

Although this theory handled a variety of findings, data that are virtually impossible to reconcile with this view were first reported by Spoehr and Corin (1978) and Campbell and Dodd (1980). In the first study, a suffix (e.g., "zero") mouthed by the experimenter and lipread by the subject produced an end-of-sequence decrement on auditorily presented digits similar to the decrement produced by a suffix spoken by the experimenter and heard by the subject. However, a card with "zero" or " 0 " written on it produced virtually no end-of-sequence decrement on auditorily presented digits. Consistent with these results are the results of Campbell and Dodd (1980), who reported that mouthed stimuli showed recency in a control condition. Furthermore, a spoken suffix resulted in typical end-of-sequence suffix effects when such stimuli were added to mouthed sequences.

These findings suggest, then, that some visual stimuli act as if they were auditorily presented. Furthermore, they underline differences between various types of visual stimuli. Where, however, do these findings leave us with respect to theoretical explanations of recency and suffix effects? In order to answer that question, it is essential to attempt to explain why lipread stimuli, which are not auditory, result in auditory-like effects. Campbell and Dodd (1980) proposed that mouthed stimuli contain changing-state temporal characteristics, and that in this respect they are like most auditory stimuli and unlike most visual stimuli, which are static. They hypothesized that this type of stimulus may be processed in such a way as to produce the recency and the accompanying end-ofsequence suffix effects characteristic of auditory stimuli.

Some data consistent with this view were presented by Shand and Klima (1981), who reported recency and suffix effects for congenitally deaf users of American Sign Language (ASL) when the signs were presented in the standard moving format. Similar results with congenitally deaf subjects using moving ASL signs and moving fingerspel- 
ling were reported by Krakow and Hanson (1985). Both Shand and Klima and Krakow and Hanson used free-recall paradigms, however, and thus their work is not definitive.

Evidence that the changing-state hypothesis is incorrect has been provided by many researchers (e.g., Campbell, Dodd, \& Brasher, 1983), including Crowder (1986), who used moving visual stimuli presented on a computer screen. In our laboratory (Manning \& Gmuer, 1985), we used the visual display of the Optacon. The Optacon, a reading aid for the blind, has a visual monitor that presents a display similar to the Times Square news display, which is clearly changing state. Neither our stimuli nor those of Crowder led to recency or end-of-sequence suffix effects. Furthermore, an earlier study in this laboratory (Manning, 1980) used stimuli produced by moving a pen across a card background without making a mark. Again, the "drawn" stimuli were changing state, but, unlike lipread stimuli, did not lead to recency or end-of-sequence suffix effects.

What, then, characterizes stimuli that produce recency and end-of-sequence suffix effects? Apparently, it is neither modality of presentation nor changing-state qualities.

Although the visual suffix effects, at least for lipread stimuli, look the same as those for auditory stimuli, the question remains as to whether they are controlled by the same mechanisms that control auditory suffix effects. Furthermore, because of the mixed results with changing-state and static visual stimuli, it has been thought that differing recall mechanisms might be at work within the visual modality, as well as between the visual and auditory modalities.

Thus, the present experiment involved an attempt to determine the role of attention in this paradigm. Since one important aspect of auditory-visual differences has been thought to relate to a subject's ability to exclude visual but not auditory stimuli from attention, it was considered important to see whether various visual stimuli were susceptible to attentional manipulations. With this goal in mind, the subjects in one condition were asked to reproduce the suffix, which was either 0 or 9 , before beginning recall, whereas those in the other condition were not. This condition, although a suffix-prefix condition, compelled attention. Prefix conditions have been shown to lead to generalized rather than end-of-sequence effects (e.g., Crowder \& Morton, 1969). However, suffixprefix conditions have been shown, when both sequences and suffixes are presented in the auditory modality, to lead to large end-of-sequence decrements in combination with the generalized decrement characteristic of the prefix condition (Manning \& Pacifici, 1983).

The use of the suffix-prefix condition, then, serves three purposes. First, it requires attention to the suffix. Second, in so doing it demonstrates the presence or absence of a standard end-of-sequence suffix effect in a condition requiring attention. Finally, it tests for the presence of a prefix effect (generalized decrements) with the various suffix-prefixes presented.

\section{METHOD}

Subjects

The subjects were 20 volunteer students from Hunter College.

\section{Materials and Design}

Each subject received 40 sequences of the digits 1-8. Sequences were constructed with the constraints that no digit could follow itself, that no digit could appear more than twice, and that only one set of consecutive numbers could appear. Additionally, "easy" sequences were discarded. The $\mathbf{4 0}$ sequences were made into five lists of $\mathbf{8}$ sequences. The digits 9 and 0 , the suffixes, were randomly assigned so that each appeared equally often in each list.

The experiment consisted of five blocks of eight trials, each with a different suffix. On all trials the numerical sequences were spoken by the experimenter. In the spoken condition, the experimenter followed each sequence with a spoken "zero" or "nine" suffix; in the mouthed condition, the same stimuli were mouthed by the experimenter. In the graphic condition, the experimenter followed each sequence by holding up a $3 \times 5$ in. index card with the number 9 or 0 written on it. In the drawn condition, the experimenter "drew" a 9 or a 0 on a blank $3 \times 5$ in. index card without making a mark on the card. In the control condition, the sequence was followed by the tapping of a pen. All suffixes were delivered in the same rhythm and for the same length of time as the items in the sequences.

Two $5 \times 5$ Greco-Latin squares were constructed and used to determine list and suffix presentation order for each subject. The assignment of one attention and one nonattention subject to each row of the GrecoLatin squares resulted in the presentation of each suffix and each list an equal number of times, and in the balancing of both suffix and list for presentation order over the entire experiment.

\section{Procedure}

The subjects were informed that they would be read lists of eightdigit sequences which they were to write down on prepared sheets, in order, from left to right. Errors were not to be corrected.

The 10 subjects in the nonattention group were told that the suffixes were of no particular importance except as recall signals. The 10 subjects in the attention group were forced to process the suffix.

In the spoken condition, subjects prefaced recall by saying "nine" or "zero," depending on which suffix was presented. Similarly, in the mouthed condition, subjects mouthed the appropriate suffix before commencing recall. In the drawn condition, they traced the nine or zero through the air with a pencil given to them; in the graphic condition, they picked up the matching card from a pair of cards, one with a 9 and one with a 0 on it. In the control condition, subjects tapped a pen before responding.

Each trial began with the word "Ready" spoken by the female experimenter, who was well practiced in using a light metronome to keep time. After a pause of $2 \mathrm{sec}$, she read the numerical sequence at the rate of about two digits per second. There was a $15-\mathrm{sec}$ recall period before the ready signal indicated the start of a new trial.

\section{RESULTS}

A response was counted as correct if and only if it was both correct and in the correct position. The mean scores for the various experimental conditions are shown in Table 1.

In the control condition, both the attention and nonattention conditions show clearcut evidence of standard recency. A 2 (attention vs. nonattention) $\times 5$ (suffix con- 
Table 1

Suffix Effects as a Function of Attentional Condition and Serial Position

\begin{tabular}{|c|c|c|c|c|c|c|c|c|}
\hline \multirow{2}{*}{$\begin{array}{c}\text { Suffix } \\
\text { Condition }\end{array}$} & \multicolumn{8}{|c|}{ Serial Position } \\
\hline & 1 & 2 & 3 & 4 & 5 & 6 & 7 & 8 \\
\hline \multicolumn{9}{|c|}{ Nonattention Condition } \\
\hline $\begin{array}{l}\text { Control } \\
\text { Spoken } \\
\text { Mouthed } \\
\text { Graphic } \\
\text { Drawn }\end{array}$ & $\begin{array}{l}7.80 \\
6.90 \\
6.90 \\
7.90 \\
7.50\end{array}$ & $\begin{array}{l}6.90 \\
6.00 \\
6.30 \\
7.20 \\
7.00\end{array}$ & $\begin{array}{l}7.10 \\
5.50 * \\
6.30 \\
6.60 \\
6.30\end{array}$ & $\begin{array}{l}7.10 \\
6.30 \\
6.00 \\
6.60 \\
6.50\end{array}$ & $\begin{array}{l}5.90 \\
4.00 * \\
5.20 \\
6.10 \\
6.30\end{array}$ & $\begin{array}{l}5.60 \\
3.40^{*} \\
4.60 \\
5.40 \\
4.60\end{array}$ & $\begin{array}{l}5.90 \\
3.30 * \\
5.30 \\
5.70 \\
5.60\end{array}$ & $\begin{array}{l}7.90 \\
3.00^{*} \\
6.60^{*} \\
7.90 \\
7.80\end{array}$ \\
\hline \multicolumn{9}{|c|}{ Attention Condition } \\
\hline $\begin{array}{l}\text { Control } \\
\text { Spoken } \\
\text { Mouthed } \\
\text { Graphic } \\
\text { Drawn }\end{array}$ & $\begin{array}{l}7.90 \\
7.30 \\
6.80 * \\
7.70 \\
7.50\end{array}$ & $\begin{array}{l}7.50 \\
6.40^{*} \\
5.50^{*} \\
7.20 \\
6.50\end{array}$ & $\begin{array}{l}6.30 \\
5.00 * \\
4.90^{*} \\
6.70 \\
6.00\end{array}$ & $\begin{array}{l}6.40 \\
5.40 \\
4.40 * \\
7.00 \\
5.90\end{array}$ & $\begin{array}{l}5.90 \\
3.60^{*} \\
3.30^{*} \\
6.10 \\
4.90\end{array}$ & $\begin{array}{l}4.30 \\
3.50 \\
3.00 * \\
4.50 \\
4.10\end{array}$ & $\begin{array}{l}5.00 \\
3.20^{*} \\
3.50^{*} \\
5.40 \\
4.50\end{array}$ & $\begin{array}{l}7.50 \\
3.20^{*} \\
3.60^{*} \\
7.70 \\
7.10 \\
\end{array}$ \\
\hline
\end{tabular}

*Indicates a significant Dunnett test, $C-E=1.08$. The maximum score is 8.00 .

dition) $\times 8$ (serial position) analysis of variance was performed. All results are reported at the .05 level of significance.

As expected, the main effects of serial position and suffix were reliable $[F(7,126)=37.08, M S e=2.88$, and $F(4,72)=33.03, M S e=3.48]$, whereas the effect of attention was not $[F(1,18)=1.05, M S e=60.81]$. Of greater importance, however, was the significant interaction of suffix $\times$ serial position $[F(28,504)=5.51, M S e$ $=1.22]$.

Dunnett tests $(C-E=1.08)$, based on the nonsignificant attention $\times$ suffix $\times$ serial position interaction $[F(28,504)=1.04, M S e=1.22]$, were used to compare each suffix condition to its control at every serial position. The results seen in Table 1 clarify the experimental findings.

The nonattention data show a large standard end-ofsequence suffix effect combined with a smaller generalized decrement for the spoken suffix. The only other condition producing a significant performance drop is the mouthed suffix at Position 8. The attention condition shows the same pattern of results for the spoken suffix as does the nonattention condition. However, for the mouthed suffix, there is a large end-of-sequence decrement and a generalized decrement across most positions. No other Dunnett tests were significant.

Further analysis is shown in Table 2. This is a breakdown of the significant attention $\times$ suffix interaction $[F(4,72)=3.86, M S e=3.48]$. Dunnett tests using the above error term for this interaction $(C-E=.49)$ show a significant effect of the attentional (suffix-prefix) manipulation for both the drawn and mouthed conditions.
However, these effects differ. In the case of the drawn condition, as can be seen in Table 1, the effect is generalized and mainly preterminal; in the case of the mouthed condition, it is both preterminal and terminal, with the final position showing the largest effect. No significant attentional effects are shown with either the spoken or the graphic suffix.

\section{DISCUSSION}

This study provides important information about the mechanisms involved in suffix effects. First, both spoken and mouthed suffixes lead to end-of-sequence suffix effects with or without attentional suffix-prefix manipulations. However, with a mouthed suffix, the end-of-sequence effect is very small in the nonattention condition and is greatly increased by the suffix-prefix; this is not the case with a spoken suffix. Additionally, the preterminal effects characteristic of a prefix are greatly increased for the mouthed suffix, but not for the spoken suffix. The spoken suffixprefix data appear standard (see Manning \& Pacifici, 1983); however, the control data show more preterminal effects than usual. However, such findings are not unknown and should not negate the important new data presented here.

Additionally, drawn suffixes do not act in the same way as either mouthed or graphic suffixes. Unlike the former, they do not produce end-of-sequence suffix effects on auditory stimuli. Unlike the latter, they do produce generalized decrements with a suffix-prefix condition. Graphic stimuli appear to be totally ineffective in producing any effect on auditory stimuli. Thus drawn stimuli appear to be somewhere in between mouthed stimuli and graphic stimuli in the degree and type of interference they produce on auditory stimuli. A similar ordering of suffix effects appears when sequences and suffixes are the same. Mouthed stimuli produce recency and end-of-sequence suffix effects on mouthed sequences (Roberts, 1984); drawn stimuli do not produce recency, but do produce generalized suffix effects (Manning, 1980); graphic stimuli produce neither recency nor consistent suffix effects. (See Hitch, 1975, however, for a study in which graphic stimuli produced end-of-sequence suffix effects in the absence of major recency.)

Table 2

Overall Effects of the Attentional Manipulation as a Function of Suffix

\begin{tabular}{lccccc}
\hline & \multicolumn{5}{c}{ Suffix Condition } \\
\cline { 2 - 6 } & Control & Spoken & Mouthed & Graphic & Drawn \\
\hline Attention Condition & 6.35 & 4.70 & 4.37 & 6.53 & 5.81 \\
Nonattention Condition & 6.77 & 4.80 & $5.90^{*}$ & 6.67 & $6.45^{*}$ \\
\hline
\end{tabular}

*Indicates a significant Dunnett test, $C-E=.49$. The maximum score is 8.00 . 
What, then, critically determines when visual suffixes act as if they were auditorily presented? Only a few visual conditions have produced both recency and end-of-sequence suffix effects. These include mouthed and lipread stimuli in normal subjects and a small number of visual stimulus conditions for the congenitally deaf. I have already mentioned that the work with the deaf cannot be considered comparable to that with mouthed stimuli because it involves free-recall paradigms. Thus I wish to postpone consideration of this work.

Although theories have been developed (e.g., Shand \& Klima, 1981) to explain the lipreading findings, none appear at the moment to be satisfactory. A similar problem appears to exist for recency and suffix effects in general. Our best hypothesis at the moment is that the various stimuli producing recency and suffix effects are those that have a special kind of final item distinctiveness. Standard auditory stimuli apparently have such distinctiveness to a greater degree than do standard graphic stimuli. However, with effort one can lessen or eliminate auditory recency by changing this variable in a variety of ways-for example, by reducing set size (see Manning, 1984, for a discussion of situations in which this may have happened) or increasing stimulus confusability (see Darwin \& Baddeley, 1974). Similarly, one can increase graphic recency and, in fact, totally eliminate the modality effect by making a final item sufficiently distinctive (Routh \& Frosdick, 1978).

What, then, causes lipread suffixes to lead to results that are similar, at least to some degree, to those of auditory suffixes? My best guess at this point is that the close linguistic connection between lipread and spoken stimuli is at least partially involved, and that this connection somehow allows the two types of stimuli to share some amount of final item distinctiveness.

As to the preterminal effects of drawn suffixes on auditory recall, I hesitate to hypothesize why they occur. I wish to note, however, that such preterminal effects also occur on recall of sequences of drawn stimuli (Manning, 1980).

In conclusion, several things appear to be clear. Although recency and end-of-sequence suffix effects are clearly not limited to the auditory modality, lipread stimuli clearly do act differently than do auditory stimuli when attention is not compelled. As with graphic and drawn stimuli, they can be partially ignored, but, unlike the other two types of stimuli, they do produce a significant end-of-sequence decrement in both attention and nonattention paradigms. Furthermore, in common with drawn stimuli, but not with graphic stimuli, they are susceptible to attentional manipulations.

Thus, I believe it is important to state that although some visual stimuli "act auditory" in these paradigms, they are different from auditory stimuli. Additionally, visual stimuli differ from each other in these situations. Thus both inter- and intramodality differences are important in information processing in these designs, and will have to be accounted for when a comprehensive theory is developed.

\section{REFERENCES}

CAmpbell, R., \& Dodd, B. (1980). Hearing by eye. Quarterly Journal of Experimental Psychology, 32, 85-99.

CAmprell, R., Dodd, B., \& Brasher, J. (1983). The sources of visual recency: Movement and language in serial recall. Quarterly Journal of Experimental Psychology: Human Experimental Psychology, 35A, 571-587.

Crowder, R. G. (1971). The sound of vowels and consonants in immediate memory. Journal of Verbal Learning \& Verbal Behavior, 10 , 587-596.

Crowder, R. G. (1986). Auditory and temporal factors in the modality effect. Journal of Experimental Psychology: Learning, Memory \& Cognition, 12, 268-278.

CROWDER, R. G., \& MORTON, J. (1969). Precategorical acoustic storage (PAS). Perception \& Psychophysics, 5, 365-373.

DARWIN, C. J., \& BADDELEY, A. D. (1974). Acoustic memory and the perception of speech. Cognitive Psychology, 6, 41-60.

HITCH, G. J. (1975). The role of attention in visual and auditory suffix effects. Memory \& Cognition, 3, 501-505.

KRAKOW, R. A., \& HaNSON, V. L. (1985). Deaf signers and serial recall in the visual modality: Memory for signs, fingerspelling, and print. Memory \& Cognition, 13, 265-272.

ManNING, S. K. (1980). Tactual and visual alphanumeric suffix effects. Quarterly Journal of Experimental Psychology, 32, 257-267.

MANNING, S. K. (1984). Effects of difficulty variables and type of suffix on serial recall. American Journal of Psychology, 97, 77-87.

MANNING, S. K., \& GMUER, B. A. (1985). Visual suffix effects on the Optacon: A test of changing state, primary linguistic, and attentional theories. Bulletin of the Psychonomic Society, 23, 1-5.

Manning, S. K., \& PACIFICI, C. (1983). The effects of a suffix-prefix on forward and backward serial recall. American Journal of Psychology, 96, 127-134.

ROBERTS, T. (1984). Auditory and temporal factors in the modality effect. Unpublished honors project, Hunter College of the City University of New York.

Routh, D. A., \& FrosDick, R. M. (1978). The basis and implications of the restoration of a recency effect in immediate serial recall. Quarterly Journal of Experimental Psychology, 30, 201-220.

Shand, M. A., \& Kuma, E. S. (1981). Nonauditory suffix effects in congenitally deaf signers of American Sign Language. Journal of Experimental Psychology: Human Learning \& Memory, 1, 464-474.

SPOEHR, K. T., \& CoRIN, W. J. (1978). The stimulus suffix effect as a memory coding phenomenon. Memory \& Cognition, 6, 583-589.

(Manuscript received for publication April 11, 1987.) 